\title{
Morphology of axonal transport abnormalities in primate eyes
}

\author{
RONALD L. RADIUS AND DOUGLAS R. ANDERSON \\ From the William L. McKnight Vision Research Center, Bascom Palmer Eye Institute, \\ Department of Ophthalmology, University of Miami School of Medicine, Miami, Florida; and the \\ Eye Institute, Medical College of Wisconsin, Milwaukee, Wisconsin, USA
}

SUMMARY The ultrastructure of the retina and optic nerve head was studied in primate eyes after central retinal artery occlusion. Within 2 hours of the vascular occlusion the inner retinal layers undergo watery (isosmotic) swelling. This watery swelling of axons and astroglia extends into the nerve head as far back as the anterior boundary of the scleral lamina cribrosa. The swelling is increased 4 hours after the occlusion, and by 24 hours disintegration has occurred. At the optic nerve head mitochondria and vesicles of smooth endoplasmic reticulum begin to accumulate within 2 hours. The accumulation increases at 4 hours and persists to 24 hours. The watery swelling seems characteristic of ischaemic axons. Membranous organelles accumulate at the boundary of an ischaemic zone when material carried by axonal transport is brought via the healthy axon segment to the boundary, but they cannot proceed further into the ischaemic zone. Such accumulation is typical of locations where rapid orthograde axonal transport or retrograde axonal transport is blocked. In contrast, when slow axonal flow is impaired, the swelling is characterised by an excess of cytoplasmic gel without a marked accumulation of organelles. Rapid orthograde transport and retrograde transport seem to be closely related to one another, while slow axoplasmic flow seems fundamentally different. From morphological findings we suspect that, in experimental glaucoma, intraocular pressure first affects the intracellular physiological process of rapid orthograde and retrograde axonal transport. Watery swelling may not occur unless the ischaemic injury to cell metabolism is more advanced. In contrast, in experimental papilloedema, the swelling results predominantly from impaired slow axoplasmic flow.

When a partial ligature impairs slow axoplasmic flow, the axon swells proximal to the blockade. ${ }^{1(p p . ~ 326-7) ~} 23$ After axonotomy, end-bulb swellings are evidently produced by material brought to the site by rapid orthograde axonal transport or retrograde axonal transport. ${ }^{1}$ (p. 331) 4-11

Ischaemia also produces axonal swelling. ${ }^{12-14}$ This swelling is not the result of impaired rapid or slow axonal transport but occurs in the midst of the region where rapid axonal transport is prevented by the lack of oxygen, and occurs too rapidly to be the result of slow axonal flow. Moreover, ischaemic swelling occurs in non-neuronal tissues where axonal transport is not a consideration. ${ }^{15}$

Thus there are several possibly independent mechanisms for axonal swelling: impaired slow Correspondence to Douglas R. Anderson, MD, Bascom Palmer Eye Institute, PO Box 016880, Miami, Florida 33101, USA. axoplasmic flow, impaired rapid orthograde axonal transport, impaired retrograde axonal transport, and ischaemic impairment of the physiological processes responsible for the control of intracellular volume.

We sought to clarify whether or not there were specific morphological features that correlate with the different pathophysiological processes that produce axonal swelling. To do this we studied the swelling of nerve fibres produced by central retinal artery occlusion in monkeys. This experimental model produces ischaemia of the inner retina. The changes within the retina are those of ischaemia, and changes at the boundary of the ischaemia in the optic disc are the result of blocked retrograde axonal transport. To achieve a correlation of abnormal morphology with the nature of the pathophysiology the findings in this model are compared and contrasted 


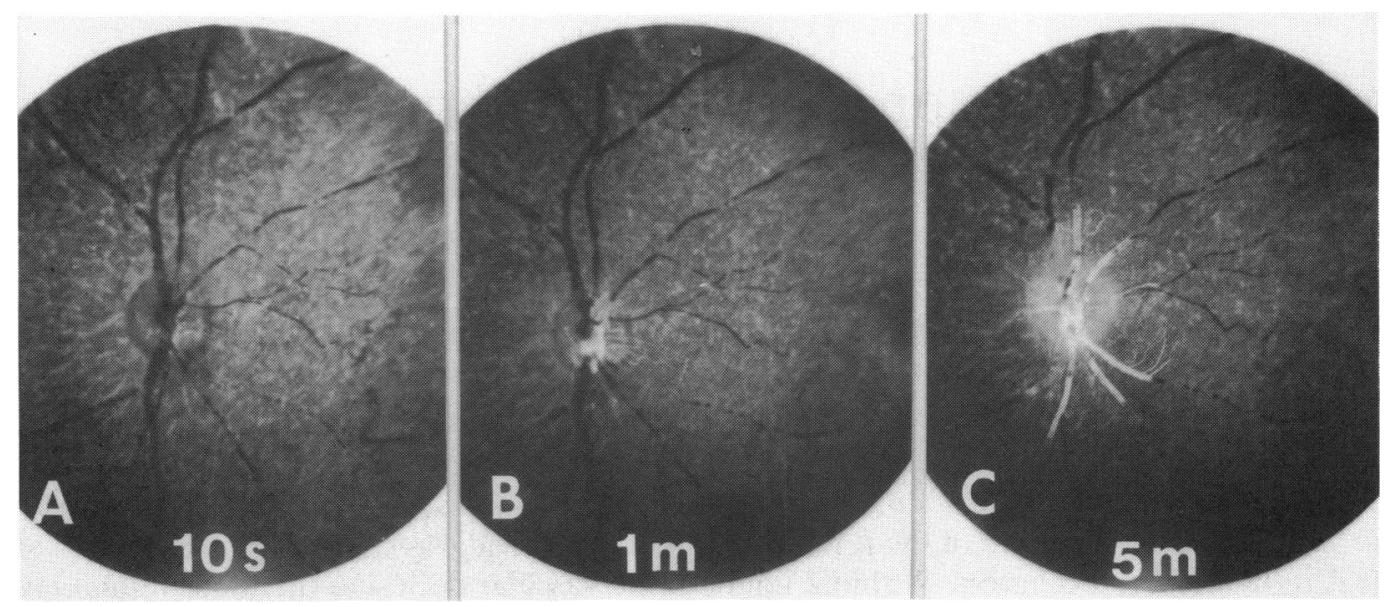

Fig. 1 Fluorescein angiogram of an owl monkey (Aotus trivirgatus) performed immediately after surgical ligation of the central retinal artery at its point of entry into the optic nerve. Ten seconds after intravenous injection of fluorescein $(0 \cdot 3 \mathrm{ml}$, $10 \%$ ) a normal pattern of choroidal fluorescence is noted; however, no perfusion of retinal vasculature is evident (A) One minute after injection, filling of the superficial nerve head microcirculation is apparent together with some retrograde flow of dye material into the major retinal arterial branches (B). Continued filling of these vessels occurs late into the angiogram sequence (5 minutes, $\mathrm{C}$ ).

with those in other experimental conditions already reported. Particular attention is given to the morphology associated with impaired axonal transport under various experimental conditions.

\section{Materials and methods}

With a technique similar to that used in previous experiments ${ }^{13}$ the central retinal artery was ligated in 11 primate eyes (Aotus trivirgatus). Throughout the surgical manipulation these animals were maintained in a sedated state by a single intraperitoneal injection of $0 \cdot 1 \mathrm{ml}$ pentobarbital $(100 \mathrm{mg} / \mathrm{ml})$ and repeated intramuscular injections of $0.1 \mathrm{ml}$ ketamine $(50$ $\mathrm{mg} / \mathrm{ml}$ ). A lateral orbitotomy was performed to expose the posterior orbit. The conjunctiva was incised and retracted, and the lateral rectus and inferior oblique muscles were disinserted. The central retinal artery was identified near its point of entry into the optic nerve. The artery was freed from neighbouring structures, including the central retinal vein, by blunt dissection while minimal bleeding was controlled by gentle pressure. A single 6-0 black silk suture was placed around the artery and tied securely, occluding the vascular lumen. The conjunctival and skin incisions were closed with multiple interrupted 4-0 black silk sutures. After colour fundus photographs were taken, fluorescein angiography was performed in each experimental eye $(0.3 \mathrm{ml}$ of $10 \%$ fluorescein, Fundescein) in order to confirm the lack of blood flow in the retinal vasculature.
After various intervals of retinal ischaemia including one-half ( 2 eyes), 1 ( 1 eye), 2 ( 2 eyes), 4 (4 eyes), and 24 ( 2 eyes) hours, ocular specimens were fixed in situ by intra-arterial perfusion (retrograde into the carotid arteries via the abdominal aorta), of $200 \mathrm{ml}$ normal saline followed by $300 \mathrm{ml}$ of buffered gluteraldehyde fixative $(\mathrm{pH} \mathrm{7.4)}$. These specimens were quickly enucleated after perfusion and immersed in fixative. Additional gluteraldehyde fixative was injected into the vitreous cavity of each eye. Twenty-four hours later tissue blocks containing specimens of perimacular retina and optic nerve head were excised, trimmed, and postfixed in osmium tetroxide. After dehydration in a graded series of ethyl alcohol and clearing in propylene oxide the specimens were embedded in epoxy resin (Epon). Thick sections $(2 \mu \mathrm{m})$ were cut and stained with paraphenylene diamine for examination by phase-contrast light microscopy. Thin sections were cut from representative areas of the retina and nerve head and counterstained with uranyl acetate and lead citrate for routine transmission electron microscopy.

\section{Results}

After ligation of the central retinal artery fluorescein angiography demonstrated occlusion of the central retinal artery (Fig. 1). Slow filling of the retinal vessels was observed over 2 to 3 minutes, apparently via retrograde perfusion of the major vasculature at the nerve head by small superficial vessels on the disc. 


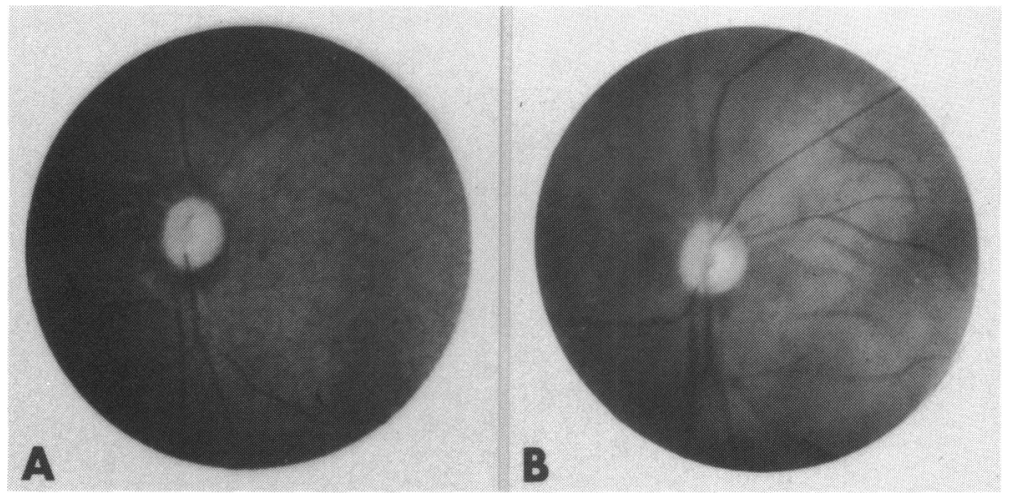

Fig. 2 Fundus photographs of a normal primate eye (Aotus trivirgatus) after surgical ligation of the central retinal artery. Immediately after closure of the vessel nerve head pallor and segmentation of blood flow within the retinal vasculature is apparent (A). After 24 hours of occlusion a grey discoloration of the retina is seen, together with thickening of the retina (B). These findings are typical of ischaemic swelling of the inner retinal layers.

Retrograde filling of the central retinal artery would appear to reflect collateral flow of blood from deeper nerve head vasculature perfused by the posterior ciliary vasculature.

In each eye the optic nerve head immediately became pale and the arteries became segmented (Fig. 2). A grey discoloration of the retina was noted at 4 hours and was quite pronounced by 24 hours after vascular occlusion (Fig. 2). In most animals the grey discoloration extended into and invaded the optic nerve head tissue, but in a few a narrow whitened zone marked the boundary of ischaemic retina with a normal-appearing disc, similar to that illustrated in Fig. 5 of a previous study ${ }^{13}$ and also observed clinically. ${ }^{16}$ No cilioretinal circulation or persistent peripapillary perfusion of retinal tissue was noted in any of these animals.

Eyes examined by phase-contrast light microscopy
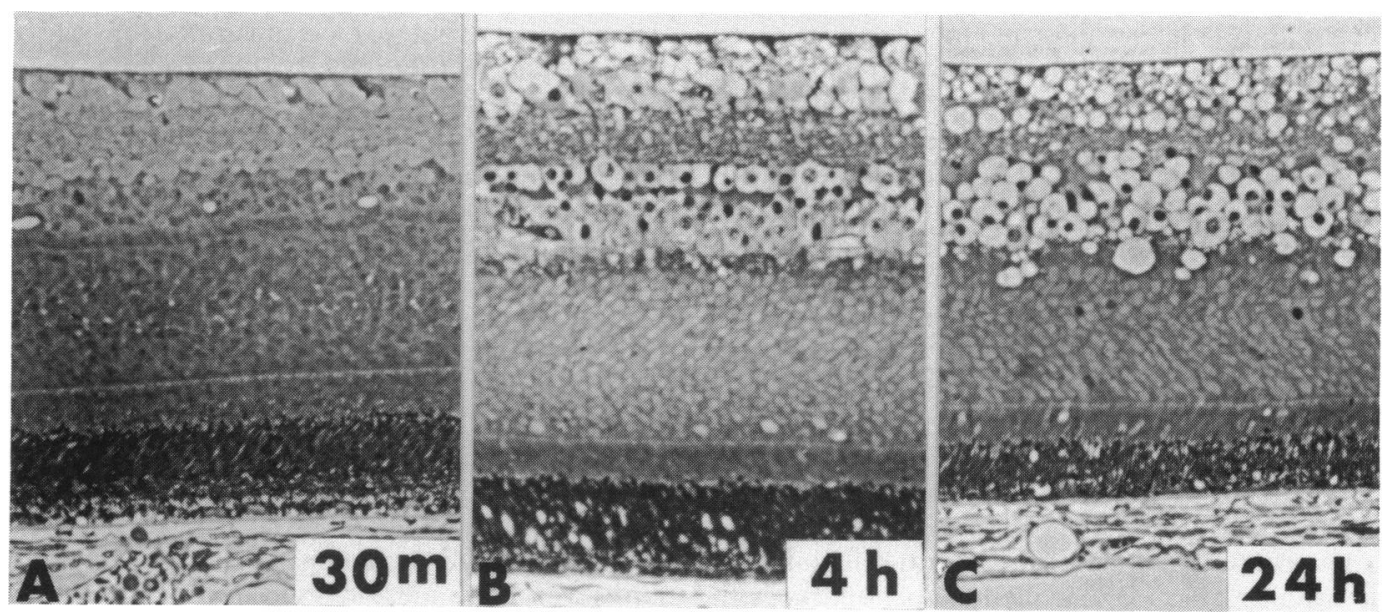

Fig. 3 Phase-contrast light photomicrographs of primate retina from specimens examined at various intervals after central retinal artery occlusion. Thirty minutes after vascular occlusion essentially no tissue abnormality was noted in the retinal nerve fibre and ganglion cell layers (A). After 4 hours of ischaemia marked vacuolation and thickening of these inner retinal layers is evident (B). By 24 hours gross disorganisation of inner retina is evident with hydropic degeneration of ganglion cells and general dissolution of all cellular outline within the nerve fibre layer (C). (Paraphenylene diamine, $\times 200)$. 


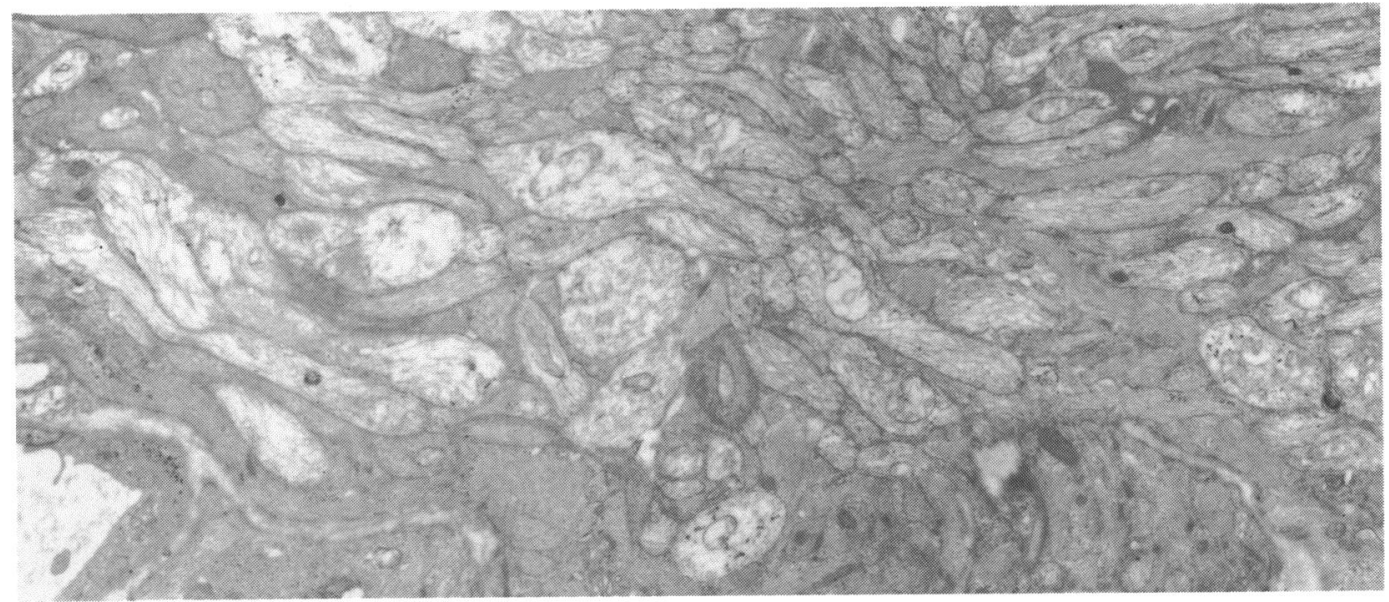

Fig. 4 Electron micrograph of the region of the optic nerve head of primate eye examined 30 minutes after occlusion of the central retinal artery. Some mild degenerative changes are apparent with scattered swollen mitochondria and some dissolution of cytoplasmic detail within nerve head axons. $(\times 8000)$.

30 minutes after central retinal artery occlusion had essentially normal histological findings (Fig. 3). However, within 1 to 2 hours of the vascular occlusion specimens contained areas of tissue degeneration including hydropic swelling and vacuolation of the retinal nerve fibre and ganglion cell layers, in addition to the inner plexiform layer, similar to the findings in a previous study.$^{13}$ After 4 hours of retinal ischaemia there was marked vacuolation and thickening of the retinal nerve fibre and ganglion cell layers (Fig. 3). Twenty-four hours after arterial occlusion, gross disorganisation of the retinal nerve fibre layer was evident with cellular swelling and membrane rupture seen as far back as the anterior (prelaminar) optic nerve head. Red cells were identified within retinal vasculature within the retina and anterior optic nerve head. This finding seemingly indicates that the central retina artery was effectively occluded so that the retinal vessels were not rinsed out with the saline and fixative. In contrast, the vessels in the prelaminar, laminar, and retrolaminar optic nerve were cleared of red blood cells, presumably because of the perfusion with saline and fixative. This indicates that the vessels supplying the nerve head were patent and capable of carrying some blood flow.

By electron microscopy specimens of retina and optic nervehead examined as early as 30 minutes after vascular occlusion contained areas with cell body and axon swelling (Fig. 4). Swollen mitochondria with some dissolution of normal cytoplasmic detail could be identified in scattered fibres. After 1 to 2 hours of retinal ischaemia these changes were more extensive, and in some axons the swelling spread as far back as the posterior lamina cribrosa and slightly into the retrolaminar myelinated optic nerve. Presumably the optic nerve head therefore was suffering some deficiency of blood flow even if the vessels were patent. By 4 hours many axons were markedly swollen with general disruption of their cytoarchitecture, including rupture of the plasma membrane (Fig. 5). The astroglia of the optic nerve head were also swollen but to a lesser degree. Finally, specimens from eyes studed 24 hours after vascular occlusion had degenerative changes involving most, if not all, optic nerve tissue elements (Fig. 6).

These hydropic changes are seen within both retina and optic nerve, but we have illustrated only the optic nerve, because the retinal ultrastructure changes were illustrated previously. ${ }^{13}$ Moreover, the optic nerve head (but not the retina) shows a second type of change, the microvesicles and dense membranous bodies. This accumulated material was noted in scattered axons in one specimen studied after 2 hours of ischaemia. In eyes studied after 4 hours of occlusion material pile-up was seen consistently (Fig. 5). Eyes studied 24 hours after occlusion of the central retinal artery contained even more marked accumulation of these organelles (Fig. 6). Accumulation was not confined to one region of the nerve head. Normal axons were intermixed with bundles of affected fibres throughout all levels of the optic nerve head including the peripapillary nerve fibre layer, the anterior optic nerve head, and the lamina cribrosa. This suggests that the boundary between the totally ischaemic and the normal segments as a diffuse zone in those particular experiments, accounting for the fact that the accumulated organelles were in most animals not 


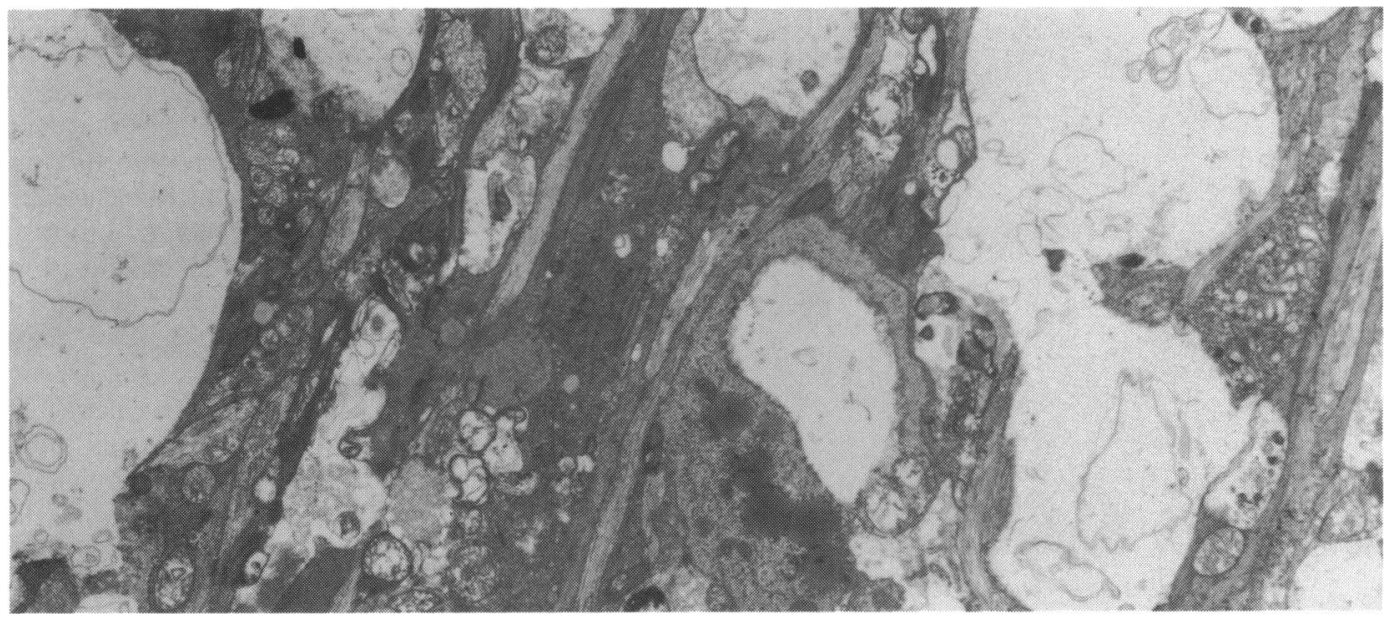

Fig. 5 Electron micrograph of optic nerve head after 4 hours of ischaemia. More extensive changes are obvious with gross swelling of some axons and most mitochondria. $(\times 8000)$.

identified ophthalmoscopically as a clear-cut boundary of white material.

\section{Discussion}

Two distinct morphological alterations of axons are seen in the present experiment. The first is watery swelling and disintegration of the axons in the retinal nerve fibre layer throughout the ischaemic retina. The second is an accumulation of membranous micro-organelles (smooth endoplasmic reticulum and mitochondria) and dense bodies at the boundary between the ischaemic and nonischaemic segments of the axons.

This pattern of 2 morphological alterations has been seen under other experimental conditions. Shakib and Ashton ${ }^{12}$ produced patches of retinal ischaemia experimentally and observed hydropic swelling at the centre of the lesion with accumulation of dense bodies at the boundary of the ischaemic patch of retina.

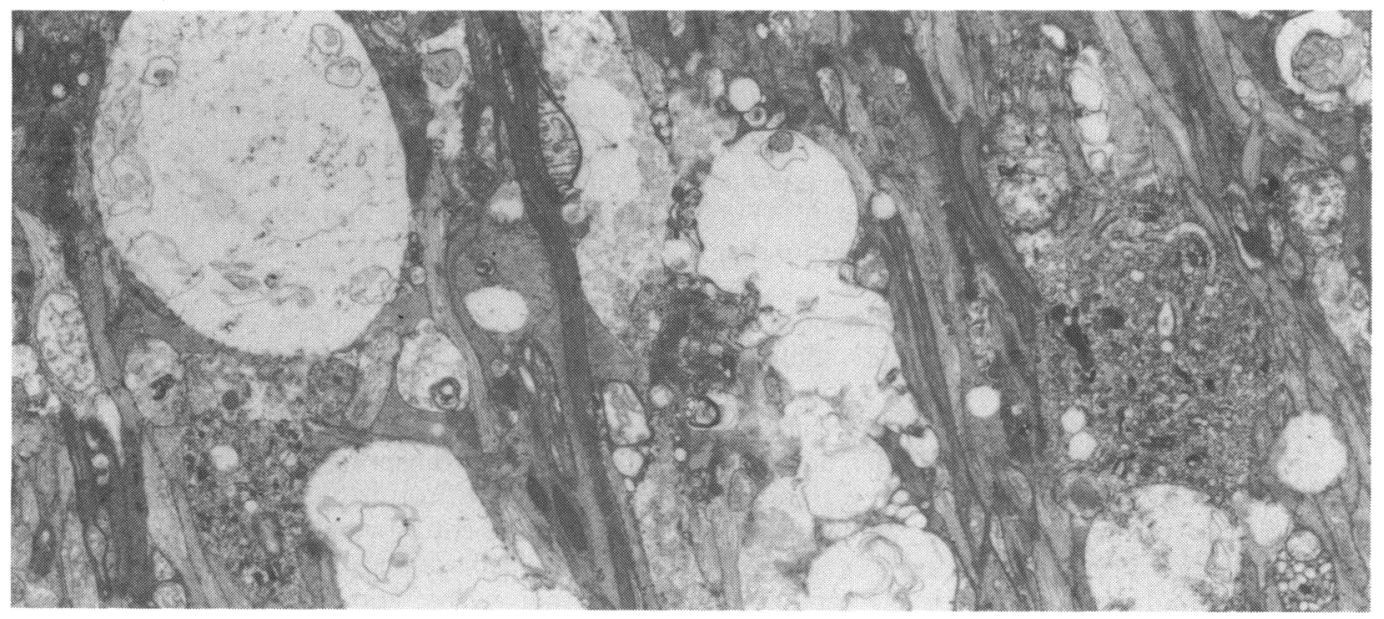

Fig. 6 Electron micrograph of optic nerve head after 24 hours of central retinal artery occlusion. These degenerative changes have increased with scattered axons suffering disruption of normal cytoreticulum, including membrane rupture and loss of cellular outline. Glial tissue was less severely involved at all time intervals studied. In addition to this watery degeneration of neural elements the axon bundles in the nerve head (but not the retina) contained an accumulation of micro-organelles including swollen mitochondria, microvesicles and dense membranous material. $(\times 8000)$. 


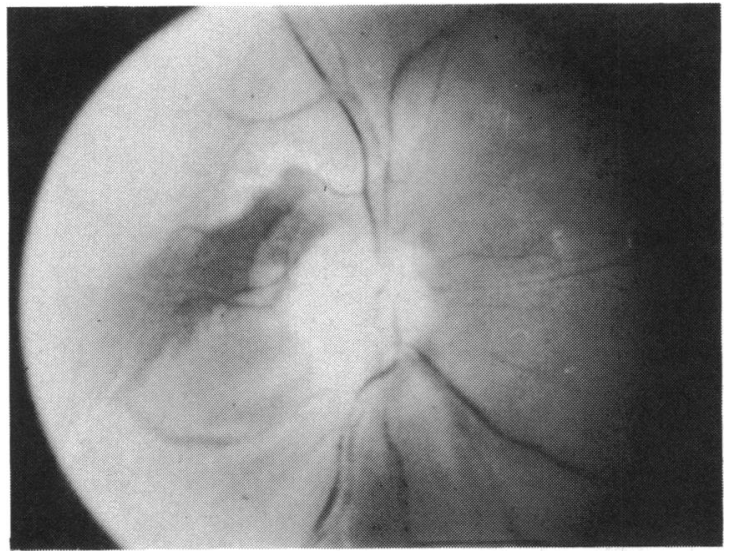

Fig. 7 Central retinal artery occlusion in a 58-year-old black man. Preservation of some retinal tissue perfusion by a cilioretinal artery is seen in the peripapillary retina. Grey discoloration of the retina reflects the hydropic degeneration of the inner retinal layers seen histologically in specimens taken from eyes with acute retinal artery occlusion. The dense white material seen in a circumferential pattern around the nerve head, on the other hand, would appear to reflect accumulation of micro-organelles normally transported retrogradely in optic nerve axons toward the ganglion cell body. Accumulation of this transported material occurs at the interface between perfused and anoxic segments of the retinal axon.

McLeod et al. ${ }^{17}$ produced similar lesions in pigs, with identical morphological findings. He observed that the hydropic swelling corresponded to a grey discoloration and thickening of the retina seen by ophthalmoscopy throughout the region affected by the retinal vascular occlusion, while the accumulation of organelles corresponded to a white 'cotton wool' material at the border of the infarct. These 2 ophthalmoscopic changes can be observed in patients with naturally occurring vascular disease ${ }^{161819}$ (Fig. 7), and presumably have a morphology corresponding to that of experimental animals.

The 2 morphological changes, though both the result of ischaemia, represent 2 different pathophysiological mechanisms. The first type, watery swelling, evidently results from passive movement of water ${ }^{13}$ (p. 468) 15 (pp. 20-22) when depletion of ATP ${ }^{20-22}$ results in a failure of the active transport pump in the axon membrane. The failing metabolism $^{21-23}$ also produces $\mathrm{pH}$ and osmotic changes in the axoplasm and surrounding tissue components. Such watery ('isomotic'15 (p. 22) or 'cytotoxic'24) swelling has been reported before in central retinal artery occlusion. ${ }^{13}$ Similar changes are seen when segments of rabbit peroneal nerves are made ischaemic,${ }^{14}$ and this form of swelling is typical of many ischaemic cells ${ }^{15}$ in addition to axons. Since the swelling which accompanies failing intracellular metabolism and disintegration of cellular components is a passive result of osmotic influences, it is natural that the degree of swelling and exact morphological appearance may depend on many factors, such as the nature and degree of the ischaemic injury, accompanying vascular changes, the composition of neighbouring tissue and intravascular fluids, existing hydrostatic tissue pressures, the type of cell in question, and the manner of fixation for microscopic examination. This variability in appearance is particularly evident in studies of brain oedema,${ }^{23-26}$ where different cells and cell types behave somewhat differently, some cells shrinking and others swelling, depending on cell type and experimental conditions.

The second type, accumulation of organelles at a particular spot in an axon, reflects a different pathophysiological process-the interruption of rapid orthograde axonal transport or the interruption of retrograde axonal transport. Rapid axonal transport requires metabolic energy. ${ }^{27}$ Therefore the accumulation of organelles occurs at the interface between normal and ischaemic tissue, because axonal transport continues in the healthy segment of the axon up to the border of the ischaemic segment-but not into the ischaemic segment. Direct evidence that the accumulated material at the edge of a retinal infarct is brought by axonal transport comes from the study of McLeod, ${ }^{16}$ who showed that radioactively tagged material carried by axonal transport accumulates among the aggregated organelles ${ }^{12} 16$ at the boundary of a patch of retinal ischaemia. He also reported ${ }^{16}$ that the material that accumulates on one border of the patch is brought by rapid orthograde axonal transport from the ganglion cell, while the material collected at the opposite border was brought there by retrograde axonal transport. Similarly, blocked rapid axonal transport occurs in the optic disc at the boundary of an ischaemic region produced by experimental occlusion of the posterior ciliary arteries. ${ }^{28}$ The whitish appearance ophthalmoscopically at the edge of the infarcted retina ${ }^{17-19}$ is identical with the 'cotton wool spot' represents a minute area of vascular insufficiency in the retina. ${ }^{2930}$ Evidently axonal transport cannot proceed through the minute area of ischaemia, and transported material collects around it and buries it to form the cotton-wool spot. Microscopically the cotton-wool spot is made up of 'cytoid bodies,' which are end-bulb swellings of the axons. ${ }^{31}$ Their microscopic appearance ${ }^{29-31}$ is identical with that of the edge of a large retinal infarct. ${ }^{12}$

There are abundant other examples in which a block of rapid axonal transport (or retrograde transport, or both) is represented by an accumulation of mitochondria, vesicles of smooth endoplasmic 
reticulum, and other dense or membraneous bodies in end-bulb swellings. Indeed there do not seem to be exceptions, and the association of blocked rapid orthograde axonal transport or retrograde axonal transport with accumulation of organelles may be universal:

(1) The end-bulb swellings which occur at both severed ends after axonotomy contain such a collection of organelles ${ }^{1}(\mathrm{p} .331)$, similar to the end-bulb swellings of cotton-wool spots already discussed. The end-bulb swellings after axonotomy were once hypothesised to represent a local reactive proliferation of organelles, but more recently it is recognised that the organelles have been delivered to the site by rapid axonal transport. ${ }^{1}$ (p. 331) 4 9-11 16 The accumulation occurs because transport cannot cross the gap where the axon is severed. The accumulation can be prevented by poisoning the axon with $\mathrm{KCl}{ }^{4}$

(2) A blockade of rapid axonal transport within an axon segment is produced by a local injection of colchicine causing an organelle accumulation at the boundary of the affected segment. ${ }^{32}$

(3) A tight ligature blocking axonal transport also results in a very rapid accumulation of mitochondria and smooth endoplasmic reticulum on both sides of the constriction. ${ }^{33-35}$

(4) Blunt trauma to the spinal cord produces an accumulation at the site of injury, ${ }^{36}$ although in this

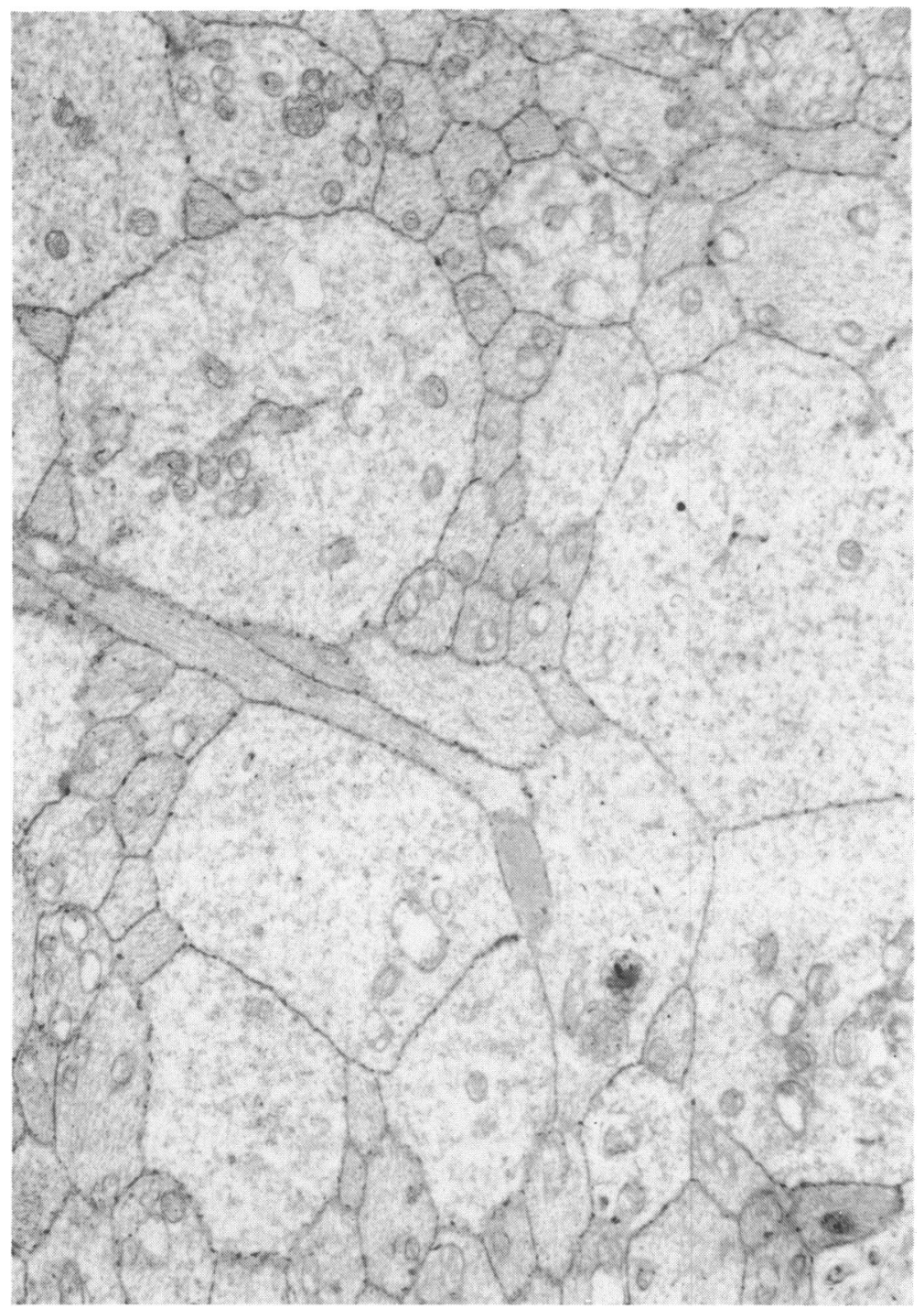

Fig. 8 Electron micrograph of the optic nerve head in experimental papilloedema produced by two days of ocular hypotony. ${ }^{74}$ Most axons are swollen with axoplasm, but there is no accumulation of micro-organelles. $(\times 8000)$. 
case it remains an assumption by analogy that axonal transport is blocked.

(5) Elevated intraocular pressure in monkeys produces a block of rapid orthograde axonal transport at the level of the lamina cribrosa ${ }^{37-47}$ as well as a block of retrograde axonal transport. ${ }^{42-43}$ There is a corresponding accumulation of microorganelles, ${ }^{4-48}$ among which can be found the radioactive tracer carried by axonal transport. ${ }^{43}{ }^{44} \mathrm{~A}$ nearly identical collection is found in the same region if the intraocular pressure is raised so high that the retina is ischaemic, preventing orthograde transport toward the optic disc. ${ }^{49}$ This seems to show that the accumulation of both mitochondria and smooth endoplasmic reticulum can be produced by retrograde transport alone, just as was true in the experiments with axonotomy or with a ligature. ${ }^{35}$ The organelle accumulation in the present experiment with central retinal artery occlusion likewise represents material brought by retrograde axonal transport, since there would not be any orthograde transport from the infarcted retina toward the disc.

The accumulations resulting from blocked retrograde transport ${ }^{493549}$ and blocked rapid orthograde transport ${ }^{4934}$ are of quite similar morphology, except for possible slight differences ${ }^{35} 49$ that were not particularly evident in the present study. This supports the view that retrograde and fast orthograde transport are 'similar processes carrying numerous organelles and constituting a system of bidirectional fast transport. ${ }^{10}$ Like orthograde transport, retrograde transport requires energy, ${ }^{50}$ continues in a segment isolated from the cell body, ${ }^{51}$ involves microtubules ${ }^{52-54}$ and smooth endoplasmic reticulum, ${ }^{105254}$ and carries some of the same substances. ${ }^{51}$ 155-57 Morphological similarities can be seen directly when rapid orthograde and retrograde transport are viewed by Nomarski microscopy. ${ }^{859}$ Some molecules even change direction in mid-course. ${ }^{106061}$ Moreover, as noted, both orthograde and retrograde transport are interrupted in concert by insults such as elevated intraocular pressure..$^{42} 43$

In contrast, slow axoplasmic flow has only been shown in an orthograde direction and consists of soluble protein (as opposed to the membraneassociated protein of fast transport).$^{62}$ Slow axonal flow is more difficult to study than rapid flow, and consequently it is less well understood. There is no universal agreement about its nature, but an attractive concept is that it can be viewed as a movement of the entire column of axoplasmic gel. ${ }^{263}$ When impaired by a constriction that does not occlude the axon completely, a swelling gradually appears proximal to the constriction, ${ }^{1-3}$ and downstream the axon becomes thinner. The swelling consists simply of an abundance of normal-appearing axoplasm, ${ }^{2}$ perhaps with a somewhat greater number of mitochondria, but there is no crowded accumulation of densely packed organelles that typifies blocked rapid orthograde or retrograde transport. Nor is there the watery cytoplasm or hydropic appearance as occurs in ischaemia or other cytotoxic swelling. It is possible to produce an impairment of slow axonal transport with $\beta, \beta^{\prime}$ iminodipropionitrile. ${ }^{64-65}$ This results in a cytoplasmic balloon $^{64} 65$ near the cell body filled with neurofilaments (carried by slow transport) but no accumulation of membranous organelles, since rapid transport is unaffected. Swelling of the optic disc in experimental papilloedema seems to be an example of impaired slow axonal flow. ${ }^{66-68}$ The morphological correlate (Fig. 8) is that the axons are engorged with relatively normal axoplasm. ${ }^{69} 70$ Occasional reactive accumulations of organelles seen in papilloedema ${ }^{69} 71$ seemingly correspond to the accompanying minor alterations in rapid axonal transport that ocurs secondarily after the axons are swollen. ${ }^{72-74}$ It can be assumed that the white accumulations resembling cotton-wool spots in severe human papilloedema represent an intensified blockage of rapid orthograde and retrograde axonal transport that can lead to axon death and visual loss.

Among the changes discussed the correlation of morphology and pathophysiology seems sufficiently strong for us to begin to use morphological criteria to identify pathophysiological events. In appropriate experiments the accumulation of organelles can be used to identify the location of blocked retrograde or rapid orthograde axonal transport. ${ }^{47-49}$ We can also now understand the report ${ }^{75}$ that in experimental acute glaucoma with severe pressure elevation there are 2 distinct morphological alterations-hydropic swelling of the axons in the optic disc and reactive collection of organelles near the lamina cribrosa. Evidently the optic nerve head was ischaemic, and the axons underwent watery swelling, accounting for the papilloedema of acute glaucoma. ${ }^{76-78}$ Meanwhile the organelles collected at the lamina cribrosa ${ }^{75}$ by retrograde axonal transport from the orbital portion of the optic nerve, just as in the central retinal artery occlusion of the present study, and in the experiment where intraocular pressure was raised above blood pressure to make all intraocular structures ischaemic. ${ }^{49}$

The block of rapid axonal transport produced by less severe conditions of elevated intraocular pressure is manifest by an organelle accumulation without watery swelling ${ }^{43-48}$ This observation could be interpreted to mean that the block in this experiment is not due to ischaemia. Or it could mean that the ischaemia is only partial-enough to block transport but not severe enough in the short term experiment to produce irreversibility of the block, ${ }^{454979}$ a lethal 
injury to the axon, or osmotic changes with hydropic swelling and axon disintegration. We can only speculate, but the latter hypothesis is plausible, since alterations in cell membrane permeability and failure of the cell membrane pumps do not occur until the cell damage is nearly irreversible ${ }^{20}$ It is quite possible that when the axons swell the ATP depletion is greater than that which produces failure of axonal transport. Thus watery swelling might not occur under conditions of partial ischaemia where the block of rapid axonal transport is still reversible, ${ }^{45}$ even if partial ischaemia is responsible for the block of axonal transport. ${ }^{79}$ Under conditions of severe ischaemia the blockade of transport may rapidly become irreversible,$^{49}$ and watery swelling might occur promptly. The same state of irreversible injury might conceivably also be reached by partial ischaemia, if prolonged.

Also noteworthy is that with elevated intraocular pressure the axons are not distended with normalappearing cytoplasm, even in the animals with chronic glaucoma ${ }^{46} 48$ where time should have been sufficient for swelling from blocked slow axonal flow to develop. From the morphology we can thus suspect that intraocular pressure produces an abnormality in rapid axonal transport through the lamina cribrosa with little or no effect on slow axoplasmic flow. It is particularly difficult to study slow axoplasmic flow in the optic nerve under conditions of experimental glaucoma, and the reported studies of slow axonal flow with radioactive tracers ${ }^{8081}$ are not as definitive as the reported block of rapid orthograde and retrograde axonal transport.

Thus, in summary, morphological observations suggest that in experimental glaucoma the predominant pathophysiological abnormality is a block of rapid transport, both orthograde and retrograde. In contrast, it seems likely that the abnormality in papilloedema is predominantly a block of slow axoplasmic flow, with secondary abnormalities in rapid transport. The fact that rapid transport and slow flow can be separately influenced under these pathological conditions, as well as with $\beta, \beta^{\prime}$-iminodipropionitrile, ${ }^{6465}$ is evidence favoring the notion that these 2 physiological processes are fundamentally different. However, rapid orthograde and retrograde transport seem to be closely related.

The experiments were conducted with the expert assistance of E. Barry Davis.

This work was supported in part by Public Health Service Research Grant EY-00031 and National Research Service Award EY-07021. both awarded by the National Eye Institute, Bethesda, Maryland. Additional support was provided by Research to Prevent Blindness. Inc., when $\mathrm{Dr}$ Anderson was named a William and Mary Greve International Research Scholar. Support is also received from the Glaucoma Research Fund of the American Health Assistance Foundation, Washington, DC.

\section{References}

1 Dahlstroem A. Axoplasmic transport (with particular respect to adrenergic neurons). Philos Trans $R$ Soc Lond (Biol) 1971; 261: 325-58.

2 Weiss PA. Neuronal dynamics and axonal flow, V. The semisolid state of the moving axonal column. Proc Natl Acad Sci USA 1972; 69: 620-3.

3 Weiss PA. Neuronal dynamics and neuroplasmic ('axonal') flow. Sym Int Soc Cell Biol 1969; 8: 3-34.

4 Friede RL. Axon swellings produced in vivo in isolated segments of nerves. Acta Neuropathol (Berl) 1964; 3: 229-37.

5 Blumcke S, Niedorf HR, Rode J. Axoplasmic alterations in the proximal and distal stumps of transsected nerves. Acta Neuropathol (Berl) 1966; 7: 44-61.

6 Lampert PW. A comparative electron microscopic study of reactive, degenerating, regenerating, and dystrophic axons. $J$ Neuropathol Exp Neurol 1967; 26: 345-68.

7 Duce IR, Keen P. Proceedings: A light and electron microscopic study of the accumulation of material in sectioned rat dorsal roots and the effect of demecolcine. Br J Pharmacol 1975; 55: $265 \mathrm{P}$

8 Zelena J, Lubinska L, Gutmann E. Accumulation of organelles at the ends of interrupted axons. Zellforsch Mikrosk Anat 1968; 91: 200-19.

9 Griffin JW, Drachman DB. Price DL. Fast axonal transport in motor nerve regeneration. J Neurobiol 1976; 7: 355-70.

10 Griffin JW. Price DL. Engel WK. Drachman DB. The pathogenesis of reactive axonal swellings: role of axonal transport, $J$ Neuropathol Exp Neurol 1977; 36: 214-27.

11 Kao CC. Chang LW. Bloodworth JM Jr. Electron microscopic observations of the mechanisms of terminal club formation in transected spinal cord axons. J Neuropathol Exp Neurol 1977; 36: $140-56$.

12 Shakib M. Ashton N. Ultrastructural changes in focal retinal ischaemia. Br J Ophthalmol 1966; 50: 325-84.

13 Kroll AJ. Experimental central retinal artery occlusion. Arch Ophthalmol 1968; 79: 453-69.

14 Tucek S, Hanzlikova V, Stranikova D. Effect of ischemia on axonal transport of choline acetyltransferase and acetylcholinesterase and on ultrastructural changes of isolated segments of rabbit nerves in situ. J Neurol Sci 1978; 36: 237-46.

15 Trump BF. Arstila AU. Cell reaction to injury. In: LaVia MF, Hill RB. eds. Principles of Pathology. 2nd ed. New York: Oxford University Press. 1975: 9-96.

16 McLeod D. Ophthalmoscopic signs of obstructed axoplasmic transport after ocular vascular occlusions. Br J Ophthalmol 1976; 60: 551-6.

17 McLeod D. Marshall J. Kohner EM. Bird AC. The role of axoplasmic transport in the pathogenesis of retinal cotton-wool spots. Br J Ophthalmol 1977; 61: 177-91.

18 McLeod D. Clinical sign of obstructed axoplasmic transport. Lancet 1975; ii: 954-7.

19 McLeod D, Oji EO, Kohner EM. Marshall J. Fundus signs in temporal arteritis. Br J Ophthalmol 1978; 62: 591-4.

20 Trump BF, Mergner WJ, Won Kahng M. Saladino AJ. Studies on the subcellular pathophysiology of ischemia. Circulation 1976; 53 (suppl 1) 1-17.

21 Siesjo BK. Ljunggren B. Cerebral energy reserves after prolonged hypoxia and ischemia. Arch Neurol 1973; 29: 400-7.

22 Drewes LR, Gilboe DD. Betz AL. Metabolic alterations in brain during anoxic-anoxia and subsequent recovery. Arch Neurol 1973; 29: 385-90

23 Garcia JH, Lossinsky AS. Kauffman FC. Conger KA. Neuronal ischemic injury: light microscopy, ultrastructure and biochemistry. Acta Neuropathol (Berl) 1978; 43: 85-95.

24 Bakay L, Lee JC. The effect of acute hypoxia and hypercapnia on the ultrastructure of the central nervous system. Brain 1968; 91: 697-706.

25 Brierley JB, Meldrum BS, Brown AW. The threshold and neuro- 
pathology of cerebral 'anoxic-ischemic' cell change. Arch Neurol $1973 ; 29: 367-74$

26 Brierley JB. Cerebral hypoxia. In: Blackwood W, Corsellis JAN. Greenfield's Neuropathology. 2nd ed. London: Arnold, 1976: 43-85.

27 Ochs S. Energy metabolism and supply of $\mathrm{P}$ to the fast axoplasmic transport mechanism in nerve. Fed Proc 1974; 33: 1049-58.

28 McLeod D. Marshall J. Kohner EM. Role of axoplasmic transport in the pathophysiology of ischaemic disc swelling. $\mathrm{Br} J$ Ophthalmol 1980; 64: 247-61.

29 Christensen L. The nature of the cytoid body. Trans Am Ophthalmol Soc 1958: 56: 451-73.

30 Hogan MJ. Zimmerman LE. ed. Ophthalmic Pathology: An Atlas and Textbook. 2nd ed. Philadelphia: Saunders. 1962:496-8.

31 Wolter JR. Pathology of a cotton-wool spot. Am J Ophthalmol 1959; 48: 473-85

32 Rodriguez Echandia EL. Ramirez BU, Fernandez HL. Studies on the mechanism of inhibition of axoplasmic transport of neuronal organelles. J Neurocytol 1973; 2: 149-56.

33 Schlaepfer WW. Effects of nerve constriction on oxygenated excised segments of rat peripheral nerve. J Neuropathol Exp Neurol 1973: 32: 203-8.

34 Kapeller K. Mayor D. An electron microscopic study of the early changes proximal to a constriction in sympathetic nerves. Proc $R$ Soc Lond (Biol) 1969; 172: 39-51.

35 Kapeller K. Mayor D. An electron microscopic study of the early changes distal to a constriction in sympathetic nerves. Proc $R$ Soc Lond (Biol) 1969; 172: 53-63.

36 Bresnahan JC. An electron-microscopic analysis of axonal alterations following blunt contusion of the spinal cord of the rhesus monkey (Macaca mulatta). J Neurol Sci 1978; 37: 59-82.

37 Quigley HA. Anderson DR. Distribution of axonal transport blockade by acute intraocular pressure elevation in the primate optic nerve head. Invest Ophthalmol Visual Sci 1977; 16: $640-4$.

38 Quigley HA, Guy J, Anderson DR. Blockade of rapid axonal transport: Effect of intraocular pressure elevation in primate optic nerve. Arch Ophthalmol 1979; 97: 525-31

39 Hayreh SS, March W, Anderson DR. Pathogenesis of block of rapid orthograde axonal transport by elevated intraocular pressure. Exp Eve Res 1979; 28: 515-23.

40 Radius RL. Schwartz EL. Anderson DR. Failure of unilateral carotid artery ligation to affect pressure-induced interruption of rapid axonal transport in primate optic nerves. Invest Ophthalmol Visual Sci 1980; 19: 153-7.

41 Radius RL. Anderson DR. Breakdown of the normal optic nerve head blood-brain barrier following acute elevation of intraocular pressure in experimental animals. Invest Ophthalmol Visual Sci 1980; 19: 244-55.

42 Minckler DS, Bunt AH, Johanson GW. Orthograde and retrograde axoplasmic transport during acute ocular hypertension in the monkey. Invest Ophthalmol Visual Sci 1977; 16: 426-41.

43 Minckler DS, Bunt AH, Klock IB. Radioautographic and cytochemical ultrastructural studies of axoplasmic transport in the monkey optic nerve head. Invest Ophthalmol Visual Sci 1978; 17: 33-50.

44 Anderson DR. Hendrickson A. Effect of intraocular pressure on rapid axoplasmic transport in the monkey optic nerve. Invest Ophthalmol Visual Sci 1974; 13: 771-83.

45 Quigley HA. Anderson DR. The dynamics and location of axonal transport blockade by acute intraocular pressure elevation in primate optic nerve. Invest Ophthalmol Visual Sci 1976; 15: 606-16.

46 Quigley HA, Addicks EM. Chronic experimental glaucoma in primates. II. Effect of extended intraocular pressure elevation on optic nerve head and axonal transport. Invest Ophthalmol Visual Sci 1980; 19: 137-52.

47 Radius RI, Anderson DR. Rapid axonal transport in primate optic nerve: distribution of pressure induced interruption. Arch Ophthalmol 1981; 99: 650-4.
48 Gaasterland D. Tanishima T, Kuwabara T. Axoplasmic flow during chronic experimental glaucoma. I. Light and electron microscopic studies of the monkey optic nervehead during development of glaucomatous cupping. Invest Ophthalmol Visual Sci 1978; 17: 838-46.

49 Radius RL. Anderson DR. The reversibility of optic nerve damage in primate eyes subjected to intraocular pressure above systolic blood pressure. BrJ Ophthalmol in press.

50 Heslop JP. Axonal flow and fast transport in nerves. Adv Comp Physiol Biochem 1975; 6: 75-163.

51 Lubinska L. Niemierko $S$. Velocity and intensity of bidirectional migration of acetylcholinesterase in transected nerves. Brain Res 1971: 27: 329-42.

$52 \mathrm{LaVail}$ JH. LaVail MM. The retrograde intraaxonal transport of horseradish peroxidase in the chick visual system: a light and electron microscopic study. J Comp Neurol 1974: 157: 303-58.

53 Nagatsu I. Kondo Y. Kato T. Nagatsu T. Retrograde axoplasmic transport of inactive dopamine B-hydroxylase in sciatic nerves. Brain Res 1976; 116: 277-85.

54 Sotelo C. Riche D. The smooth endoplasmic reticulum and the retrograde and fast orthograde transport of horseradish peroxidase in the nigro-striato-nigral loop. Anat Embryol (Berl) 1974: 146: 209-18.

55 Hunt SP. Kuenzle H. Bidirectional movement of label and transneuronal transport phenomena after injection of $\left[{ }^{3} \mathrm{H}\right]$ adenosine into the central nervous system. Brain Res 1976; 112: 127-32.

56 Brimijoin S. Helland L. Rapid retrograde transport of dopamineB-hydroxylase as examined by the stop-flow technique. Brain Res 1976; 102: 217-28

57 Hansson HA. Uptake and intracellular bidirectional transport of horseradish peroxidase in retinal ganglion cells. Exp Eve Res 1973; 16: 377-88.

58 Leestma JE. Freeman SS. Computer-assisted analysis of particulate axoplasmic flow in organized CNS tissue cultures. $J$ Neurobiol 1977; 8: 453-67.

59 Kirkpatrick JB. Bray JJ, Palmer SM. Visualization of axoplasmic flow in vitro by Nomarski microscopy. Comparison to rapid flow of radioactive proteins. Brain Res 1972; 43: $1-10$.

60 Frizell M. McLean WG. Sjoestrand J. Retrograde axonal transport of rapidly migrating labelled proteins and glycoproteins in regenerating peripheral nerves. J Neurochem 1976; 27: 191-6.

61 Abe T. Haga T. Kurokawa M. Retrograde axoplasmic transport: its continuation as anterograde transport. FEBS Lett 1974: 47: 272-5.

62 Hoffman PN. Lasek RJ. The slow component of axonal transport: identification of major structural polypeptides of the axon and their generality among mammalian neurons. J Cell Biol 1975; 66: 351-66.

63 Anderson DR. Axonal transport in the retina and optic nerve. In: Glaser JS. ed. Neuro-ophthalmologv. Symposium of the University of Miami and the Bascom Palmer Eye Institute. St Louis: Mosby, 1977: 9: 140-53.

64 Chou S-M. Hartmann HA. Axonal lesions and waltzing syndrome after IDPN administration in rats; with a concept-'axostasis.' Acta Neuropathol (Berl) 1964; 3: 428-50.

65 Hoffman PN, Clark AW, Carroll PT. Price DL. Slow axonal transport of neurofilament proteins: impairment by $\beta, \beta^{\prime}$ iminodipropionitrile administration. Science 1978; 202: 633-5.

66 Minckler DS. Tso MOM. Zimmerman LE. A light microscopic. autoradiographic study of axoplasmic transport in the optic nerve head during ocular hypotony, increased intraocular pressure. and papilledema. Am J Ophthalmol 1976; 82: 741-57.

67 Tso MOM. Hayreh SS. Optic disc edema in raised intracranial pressure. IV. Axoplasmic transport in experimental papilledema. Arch Ophthalmol 1977; 95: 1458-62.

68 Minckler DS, Bunt AH. Axoplasmic transport in ocular hypotony and papilledema in the monkey. Arch Ophthalmol 1977: 95: $1430-6$.

69 Tso MOM, Fine BS. Electron microscopic study of human papilledema. Am J Ophthalmol 1976; 82: 424-34. 
70 Tso MOM. Hayreh SS. Optic disc edema in raised intracranial pressure. III. A pathologic study of experimental papilledema. Arch Ophthalmol 1977; 95: 1448-57.

71 Minckler DS. Tso MOM. Experimental papilledema produced by cyclocryotherapy. Am J Ophthalmol 1976; 82: 577-89.

72 Anderson DR, Hendrickson AE. Failure of increased intracranial pressure to affect rapid axonal transport at the optic nerve head. Invest Ophthalmol Visual Sci 1977; 16: 423-6.

73 Anderson DR. Papilledema and axonal transport. In: Thompson HS, Daroff R, Frisen L, Glaser JS, Sanders MD, ed. Topics in Neuro-ophthalmology. Baltimore: Williams and Wilkins. 1979 184-9.

74 Radius RL, Anderson DR. Fast axonal transport in early experimental disc edema. Invest Ophthalmol Visual Sci 1980; 19: 158-68.

75 Lampert PW, Vogel MH, Zimmerman LE. Pathology of the optic nerve in experimental acute glaucoma: electron microscopic studies. Invest Ophthalmol Visual Sci 1968; 7: 199-213.
76 Zimmerman LE, deVenecia G, Hamasaki DI. Pathology of the optic nerve in experimental acute glaucoma. Invest Ophthalmol Visual Sci 1967; 6: 109-25.

77 Zimmerman LE. Discussion. In: Armaly MF. Becker B. Haas JS et al. ed. Symposium on Glaucoma. Trans $N$ Orleans Acad Ophthalmol 1966: 1-30.

78 Kronfeld PC. Glaucoma and the optic nerve: A historical review. Surv Ophthalmol 1974; 19: 154-65.

79 Leone J, Ochs S. Anoxic block and recovery of axoplasmic transport and electrical excitability of nerve. J Neurobiol 1978: 9: 229-45.

80 Levy NS. The effects of elevated intraocular pressure on slow axonal protein flow. Invest Ophthalmol Visual Sci 1974: 13: 691-5.

81 Levy NS. The effect of elevated intraocular pressure on axoplasmic transport in the optic nerve of the rhesus monkey. Doc Ophthalmol 1977; 43: 181-216. 